\title{
Parameter Analysis on the Anti-Impact Behavior of Pcfst Columns under Lateral Impact Load
}

\author{
W Xu , A Z Zhu and K Gao \\ School of Civil Engineering and Mechanics, Hubei Key Laboratory of Control Structure, Huazhong University of Science and Technology, \\ Wuhan, P.R. China
}

\begin{abstract}
Concrete-filled steel tubular (CFST) structures have been widely used in civil engineering structures, due to its good behaviors under both static and dynamic loads. In this paper, numerical studies were carried out to investigate the anti-impact behavior of partially concrete-filled steel tubular (PCFST) columns under lateral impact loads. Finite element analysis (FEA) model was established using ABAQUS. To validate the FEA model, the numerical results were compared with experimental results. Moreover, parameter analysis was carried out to further study the anti-impact behaviors of the PCFST columns. The concrete filling height, the impact energy, the impact direction, and the yield strength of steel were the main parameters considered in this study. The dynamic responses under the impact load, including the impact force, the failure mode, and the displacement response, were all analyzed. The results of parameter analysis showed that the anti-impact behaviors of the PCFST columns significantly increased when the concrete filling height or the yield strength of steel increased greatly. The impact energy and direction also greatly affected the anti-impact behaviors of the PCFST columns.
\end{abstract}

\section{Introduction}

As a type of composite construction technique, concretefilled steel tubular (CFST) members have been widely used in civil engineering structures, owing to their large load-carrying capacity and ease of construction [1]. With the development of urban traffic, vehicle collision became one of the main reasons causing the failure of bridge piers. Otherwise, due to the defect of anti-impact device and design, bridges may be destroyed in some serious vehiclebridge collision. The design demand for structures to withstand impact load has increased, and using CFST members was expected to effectively improve structural anti-impact behaviors.

In the reality, the impact loads usually occurred near the bottom of columns rather than at the mid span [2]. Besides, partially filling concrete into hollow steel columns could help delay local buckling of the steel columns and was expected to improve the local antiimpact behaviors of the steel columns. Previously, the seismic behaviors of partially concrete-filled steel tubular (PCFST) members were investigated by Ge et al. [3] and Yuan et al. [4]. Usami et al. [5] performed cyclic and dynamic loads on PCFST bridge piers and found out that the PCFST columns showed good earthquake-resistance characteristics. However, investigations into the behaviors of PCFST columns under lateral impact loads were not found. The influence of parameters on the antiimpact behaviors of PCFST columns under impact loads were unknown.
This paper was attempted to study the behaviors of PCFST members under lateral impact loads. The columns were lateral impacted by pendulum hammer near the bottom. First, finite element models were established using ABAQUS to simulate the vehicle-pier collision. Second, the finite element models were validated by comparing the numerical results with experimental results. Third, to further study the anti-impact behaviors of PCFST columns, parameter analysis was carried out. The parameters including the concrete filling height $\left(h_{\mathrm{c}}\right)$, the impact energy $\left(E_{\mathrm{i}}\right)$, the impact direction $(\alpha)$, and the yield strength of steel $\left(f_{\mathrm{y}}\right)$ were considered. The dynamic responses under the impact load, including the impact force, the failure mode, and the displacement response, were all analyzed.

\section{Finite element model}

To simulate the actual condition, the material properties under impact load, the boundary conditions and the contact between the steel tube and the infilling concrete were considered. Details of the FEA models were shown in the following sections.

\subsection{Element mesh}

The cross-section of the rectangular steel tube was shown in figure 1. The sectional dimension of the rectangular steel tubes was $140 \times 80 \times 3 \mathrm{~mm}$. The inner radius of the 
cold-formed corner was $4.5 \mathrm{~mm}$. The total length of the columns was $1500 \mathrm{~mm}$. The impact center was at the height of $320 \mathrm{~mm}$ from the bottom. The steel tube was partially filled with concrete. The steel tube and the infilling concrete were simulated using 4-node shell element with reduced integration (S4R) and 8-node brick element with reduced integration (C3D8R), respectively. The pendulum hammer was simplified to a rigid shell surface with an initial impact velocity and a mass of 350 $\mathrm{kg}$, in order to simulate the vehicle impact. The rigid shell surface had a dimension of $200 \times 50 \mathrm{~mm}$. Furthermore, a mesh convergence study was carried out to choose an appropriate mesh density. The adopted element mesh was shown in figure 1. Moreover, stiffness-type hourglass control was used to eliminate the zero energy modes and the hourglass energy was less than $5 \%$ of total impact energy.

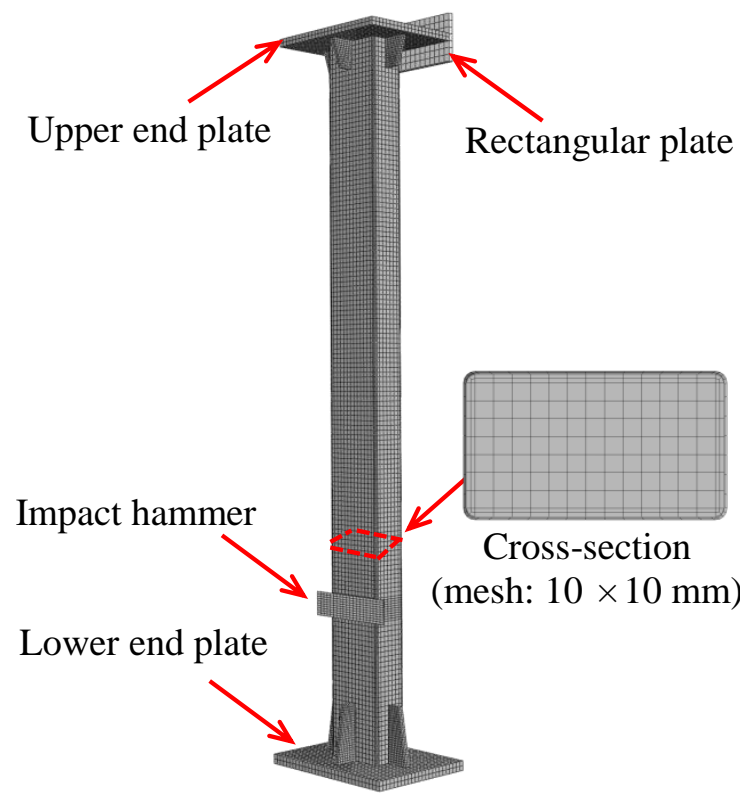

Figure 1. FEA model under lateral impact

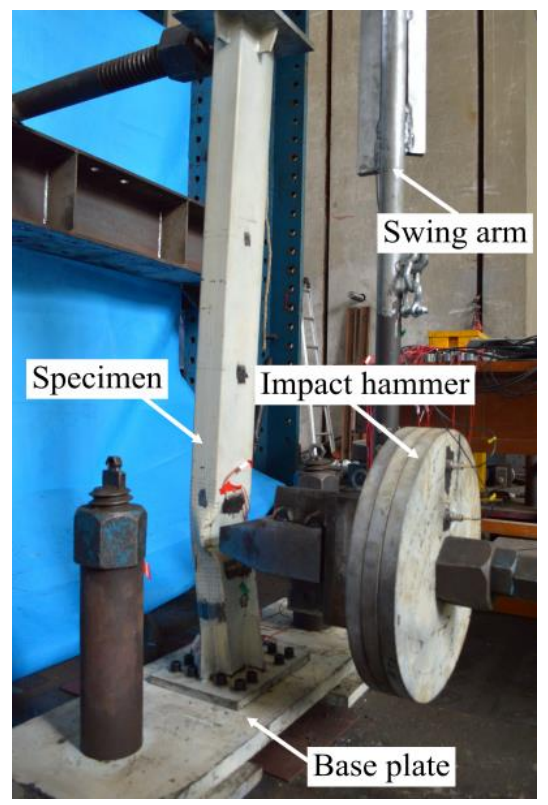

Figure 2. Test device

\subsection{Materials}

A stress-strain model for cold-formed steel with a multilinear isotropic strain hardening rule [6] was used to simulate the material of the steel tube. The cross-sections of the rectangular steel tube were divided into flat zones and corner zones. The stress-strain relationship for the flat zones and the corner zones of the cold-formed sections were different. The yield strength $\left(f_{\mathrm{y}}\right)$ and ultimate strength $\left(f_{\mathrm{u}}\right)$ of the flat zones were obtained by conducting steel tensile coupon test. The yield strength of the corner zones $\left(f_{\mathrm{yc}}\right)$ were considered in an analysis model developed by Abdel-Rahman et al. [6], which was related to the inner radius of the cold-formed corner $(r)$, the wall thickness of the steel tube $(t)$ and the material properties of the flat zones. An empirical equation for $f_{\mathrm{yc}}$ was presented by Abdel-Rahman et al. [6]. The ultimate tensile strength of the corner zones $\left(f_{\text {uc }}\right)$ was calculated by the equation (1) proposed by Tao et al. [7]. CowperSymonds power [8] was introduced to consider the effect of strain-rate $(\dot{\varepsilon})$ with a multiplier factor $(D)$ of $40.4^{-1}$ and exponent $(p)$ of 5 to achieve the dynamic yield strength .

$$
\begin{gathered}
f_{u c}=\left\{\begin{array}{l}
{\left[1.6-2 \times 10^{-3}\left(f_{y c}-200\right)\right] f_{y c}} \\
{\left[1.2-3.75 \times 10^{-4}\left(f_{y c}-400\right)\right] f_{y c}}
\end{array}\right. \\
200 M P a \leq f_{y c} \leq 400 M P a \\
400 M P a \leq f_{y c} \leq 800 M P a
\end{gathered}
$$

The concrete damage plasticity (CDP) model in ABAQUS was adopted in this FEA model to simulate the behavior of concrete. In the CDP model, dilation angle $(\psi)$, flow potential eccentricity $(e)$, the ratio of the second stress invariant on the tensile meridian to that on the compressive meridian $\left(K_{\mathrm{c}}\right)$ and ratio of the compressive strength under biaxial loading to uniaxial compressive strength $\left(f_{\mathrm{b} 0} / f_{\mathrm{c} 0}\right)$ were set as $30^{\circ}, 0.1,2 / 3$ and 1.16 [7], respectively. The stress-strain relationship of core concrete presented by Han et al. [9] was used to consider the increasing in the plasticity behavior of infilling concrete due to the passive confinement of the steel tube. The characteristic static compressive strength of concrete $\left(f_{\text {ck }}\right)$ was multiplied by a dynamic increase factor of 1.25 to consider the effect of impact load [2].

\subsection{Boundary conditions and contact}

In order to simulate the actual boundary condition of impact, the freedoms of the lower end plate were restricted. The displacement of the upper end plate along the impact direction was restricted by the rectangular plate. A surface-based interaction with a contact pressure model in the normal direction and a Coulomb friction model in the tangential direction was used to simulate the contact between steel and infilling concrete. The detail information about the interaction could be found in Han et al. [9]. The friction factor of the Coulomb friction model was taken as 0.47 [10]. 


\subsection{Validation of the FEA model}

Impact tests were performed to study the anti-impact behaviors of PCFST column. The device of the impact test, including the column specimen, the impact hammer and the base plate, was shown in figure 2 . To validate the FEA model, the numerical results including the failure mode and displacement response were compared with the experimental results, as shown in figures 3 and 4 respectively. The hollow steel tubular specimen (H0) and the PCFST specimens with concrete filling height of 700 $\mathrm{mm}$ (P700) and $1000 \mathrm{~mm}$ (P1000) were the specimens for comparisons. From figure 3 , the global flexural deformation and local buckling of the test could be well predicted by the FEA model. Especially, for P700, the local buckling near the interface between the hollow steel section and the concrete-filled steel section could also be predicted. From figure 4, the numerical and experimental displacement processes were similar, both with three stages: the rising, the rebounding, and the stable stages. The displacement peak values of the FEA model were close to the test. The mean value of the ratio $\Delta_{\text {maxFEA }} / \Delta_{\text {maxTest }}$ was 1.03 . Thus, a good agreement was achieved between the test and FEA model.
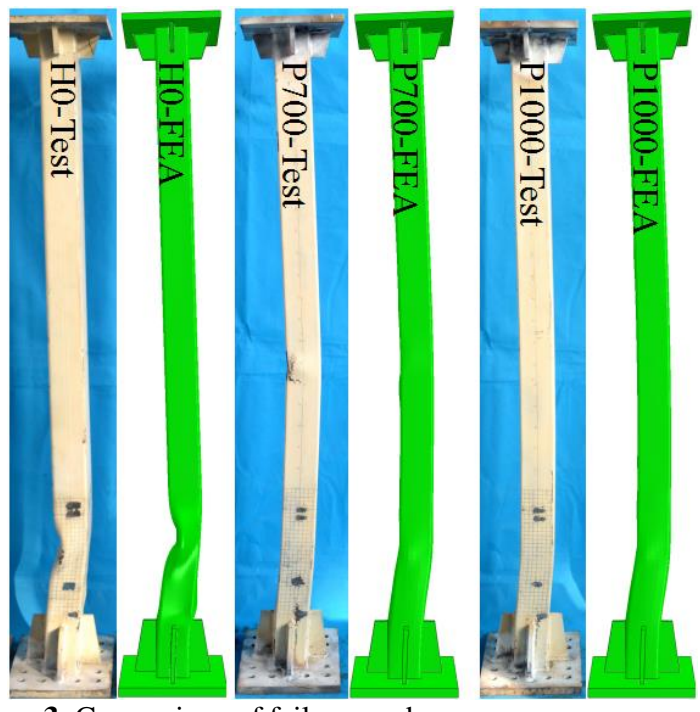

Figure 3. Comparison of failure modes

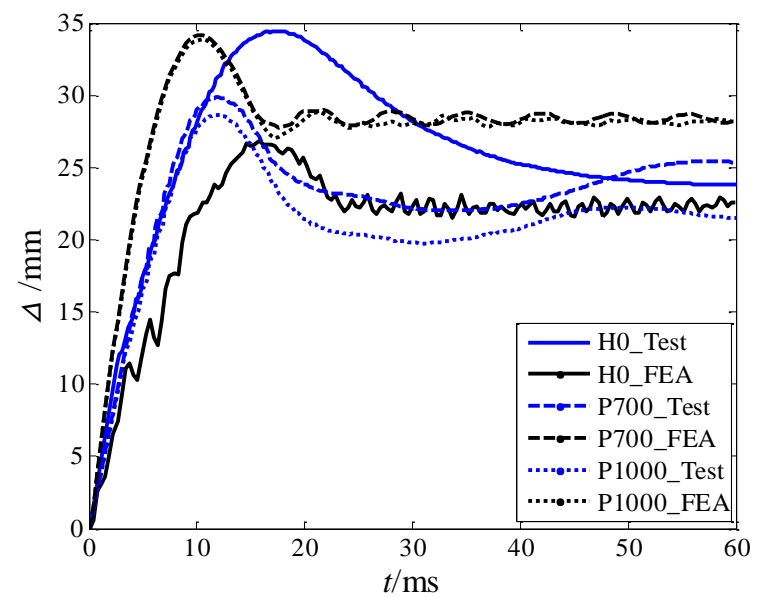

Figure 4. Comparison of displacement responses

\section{Parameter analysis}

To further study the anti-impact behaviors of PCFST columns, parameter analysis was carried out. As shown in table 1 , the parameters including the $h_{\mathrm{c}}, E_{\mathrm{i}}, \alpha$ and $f_{\mathrm{y}}$ were considered, where $\alpha$ was the angle between the impact direction and the short edge of the cross-section. Different impact energies were achieved by changing the velocity of the impact hammer. The failure mode, the post-peak mean force $\left(F_{\mathrm{m}}\right)$ and the displacement peak value $\left(\Delta_{\max }\right)$ were the dynamic responses for comparisons.

First, the concrete filling height significantly affected the anti-impact behaviors of PCFST columns. When $h_{\mathrm{c}}$ increased from $0 \mathrm{~mm}$ to $400 \mathrm{~mm}, F_{\mathrm{m}}$ significantly increased and $\Delta_{\max }$ decreased. The failure

mode of M1 was similar to $\mathrm{H} 0$ in figure 3 and local bucklings of M2-M4 near the interface between the hollow steel section and the concrete-filled steel section were similar to P700. When $h_{\mathrm{c}}$ was higher than $1000 \mathrm{~mm}$, local buckling near the interface was not observed. Furthermore, the anti-impact behavior of full concretefilled steel tubular column (M6) was similar to PCFST columns. Comparing M1 with other PCFST models (M2M5), it could be found that the anti-impact behaviors could be greatly improved by the infilling concrete.

Table 1. Parameter analysis on the anti-impact behaviors of PCFST columns

\begin{tabular}{ccccccc}
\hline Model & $h_{\mathrm{c}}(\mathrm{mm})$ & $E_{\mathrm{i}}(\mathrm{kJ})$ & $\alpha\left(^{\circ}\right)$ & $f_{\mathrm{y}}(\mathrm{MPa})$ & $F_{\mathrm{m}}(\mathrm{kN})$ & $\Delta_{\max }(\mathrm{mm})$ \\
\hline M1 & $\mathbf{0}$ & 8 & 0 & 540.6 & 104.2 & 41.5 \\
M2 & $\mathbf{4 0 0}$ & 8 & 0 & 540.6 & 227.0 & 37.6 \\
M3 & $\mathbf{7 0 0}$ & 8 & 0 & 540.6 & 223.5 & 37.0 \\
M4 & $\mathbf{8 0 0}$ & 8 & 0 & 540.6 & 218.7 & 37.0 \\
M5 & $\mathbf{1 0 0 0}$ & 8 & 0 & 540.6 & 223.3 & 36.4 \\
M6 & $\mathbf{1 5 0 0}$ & 8 & 0 & 540.6 & 230.0 & 35.4 \\
M7 & 700 & $\mathbf{5}$ & 0 & 540.6 & 202.4 & 25.4 \\
M8 & 700 & $\mathbf{6}$ & 0 & 540.6 & 204.5 & 30.0 \\
M9 & 700 & $\mathbf{7}$ & 0 & 540.6 & 216.3 & 33.8 \\
M10 & 700 & $\mathbf{8}$ & 0 & 540.6 & 223.5 & 37.0 \\
M11 & 700 & $\mathbf{9}$ & 0 & 540.6 & 228.7 & 40.6 \\
M12 & 700 & $\mathbf{1 0}$ & 0 & 540.6 & 234.1 & 43.6 \\
M13 & 700 & 8 & $\mathbf{0}$ & 540.6 & 223.5 & 37.0 \\
M14 & 700 & 8 & $\mathbf{1 5}$ & 540.6 & 227.9 & 34.2 \\
M15 & 700 & 8 & $\mathbf{3 0}$ & 540.6 & 212.9 & 31.7 \\
\hline
\end{tabular}




\begin{tabular}{lcccccc}
\hline M16 & 700 & 8 & $\mathbf{4 5}$ & 540.6 & 216.7 & 29.3 \\
M17 & 700 & 8 & $\mathbf{6 0}$ & 540.6 & 234.3 & 22.6 \\
M18 & 700 & 8 & $\mathbf{7 5}$ & 540.6 & 260.9 & 16.7 \\
M19 & 700 & 8 & 0 & $\mathbf{2 0 0}$ & 136.1 & 55.6 \\
M20 & 700 & 8 & 0 & $\mathbf{3 0 0}$ & 173.4 & 44.3 \\
M21 & 700 & 8 & 0 & $\mathbf{4 0 0}$ & 212.0 & 37.5 \\
M22 & 700 & 8 & 0 & $\mathbf{5 0 0}$ & 221.6 & 37.3 \\
M23 & 700 & 8 & 0 & $\mathbf{6 0 0}$ & 235.1 & 35.4 \\
M24 & 700 & 8 & 0 & $\mathbf{7 0 0}$ & 256.1 & 33.0 \\
\hline
\end{tabular}

Second, $\Delta_{\max }, F_{\mathrm{m}}$ and local buckling near the interface all increased with the increase of $E_{\mathrm{i}}$. The increase of local buckling indicated that the stress waves generated by larger impact energy propagated to the interface, which was the weak zone of columns. Thus, larger deformations occurred under larger $E_{\mathrm{i}}$.

Third, PCFST columns under different impact directions shown different failure modes. The local buckling near the impacted corner occurred in M14-M18, as shown in figure 5. With the increase of $\alpha$, global flexural deformations and $\Delta_{\max }$ both decreased. Thus, the bending about the weak axis of the column was the most critical situation under lateral impact load.

Last, with the increase of $f_{\mathrm{y}}$, for columns with $h_{\mathrm{c}}$ of 700 $\mathrm{mm}, F_{\mathrm{m}}$ greatly increased and $\Delta_{\max }$ decreased. Besides, as shown in figure 6 , for columns (M19-M21) with lower $f_{\mathrm{y}}$, larger local buckling near the interface and larger lateral displacement occurred in mid-span. Thus, increasing $f_{\mathrm{y}}$ could significantly improve the anti-impact behaviors of PCFST columns.

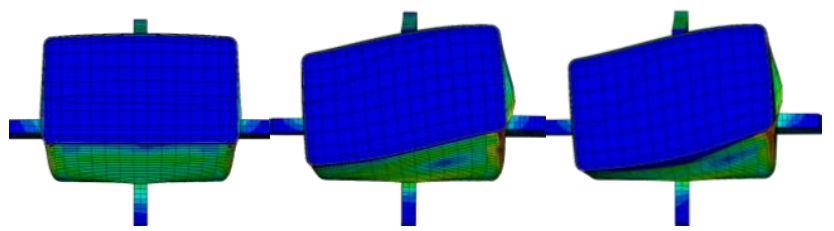

(a) M13

(b) M14

(c) M15

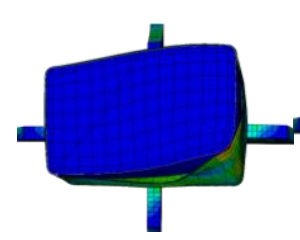

(d) M16

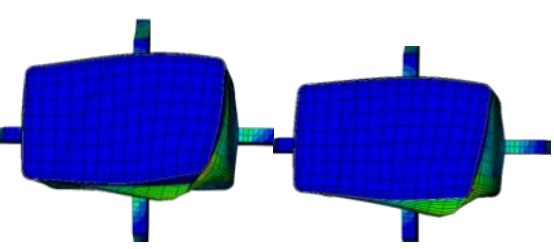

(e) M17

(f) M18

Figure 5. Local buckling near the impacted corner

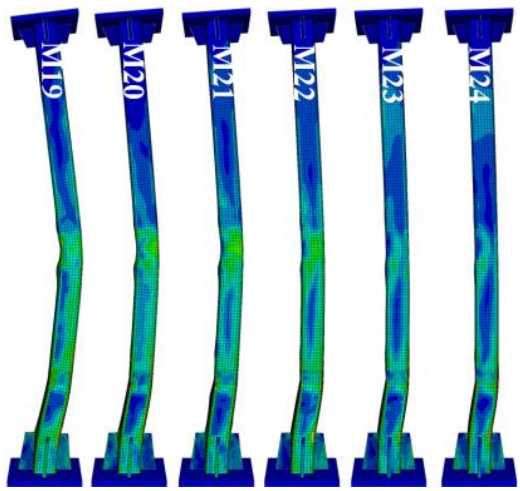

Figure 6. Failure mode of M19-M24

\section{Conclusion}

This paper presented a numerical investigation on the anti-impact behavior of PCFST columns under lateral impact load. The impact load was conducted at the height of $320 \mathrm{~mm}$ from the column bottom. A finite element model was established. The element mesh, material properties, boundary conditions, and contact were all considered in this model. Then, by comparing the numerical and experimental results, a good agreement was achieved between the test and the FEA model. Thus, the accuracy of the FEA model was validated. Parameter analysis was carried out to further study the anti-impact behavior. The results shown that the anti-impact behavior of PCFST columns increased with increasing concrete filling height and yield strength of steel. Moreover, the columns with $\alpha$ of $0^{\circ}$ were the most critical situation under impact loads. And the columns under larger impact energy was prone to larger deformation.

\section{Acknowledgement}

The authors gratefully acknowledge the supports of the National Natural Science Foundation of China (No.51378233 \& No.51629801) and the Fundamental Research Funds for the Central Universities (No.2016YXMS095).

\section{Reference}

1. Han L H, Li W and Bjorhovde R 2014 J. Construct. Steel Res. 100 211-28

2. Yousuf M, Uy B, Tao Z, Remennikov A and Richard J Y 2014 J. Construct. Steel Res. 96 54-68

3. Ge H B and Usami T 1996 J. Struct. Eng. 1221169 77

4. Yuan H H, Dang J and Aoki T 2013 Earthquake Engng Struct. Dyn. 42 2197-216

5. Usami T, Ge H B and Saizuka K 1997 Construct Steel Res. 41 121-136

6. Abdel-Rahman N and Sivakumaran K S 1997 J. Struct. Eng. 123 1135-43

7. Tao Z, Wang X Q and Uy Brain 2013 J. Mater. Civ. Eng. 25 1306-16

8. Abramowicz W and Jones N 1984 Int. J. Impact Engng. 2 179-208

9. Han L H, Yao G H and Tao Z 2007 Thin-walled Struct. 45 24-36

10. Baltay P and Gjelsvil A 1990 J. Mater. Civ. Eng. 2 46-49 